\title{
Stand-Alone Presentations: Focus on Historic Texts
}

\author{
B. H. Groff \\ Indiana University Purdue University Fort Wayne \\ Fort Wayne, Indiana 46805
}

\begin{abstract}
Organizational Leadership \& Supervision (OLS) majors at Indiana University Purdue University Fort Wayne (IPFW) need to be able to use technology to create engaging presentations for their audiences. Their audience may consist of employees wanting to view training materials at their convenience or their audience could consist of colleagues from across the globe that need to view a presentation online. OLS majors are proficient in using tools such as Microsoft PowerPoint to create presentations. However, this type of software is best suited for a live presentation. What if the slides are viewed without anyone presenting them orally; do they convey the same message? Fortunately, there are tools that allow users to easily capture and synchronize audio and video with slides from PowerPoint presentations. Adobe has developed an add-on program to PowerPoint called Presenter. Presenter turns the PowerPoint slides into an engaging, media-rich presentation that can be published to the web. This paper discusses the use of the Presenter software in OLS 324: "Advanced Word Processing, Desktop Publishing, and Presentation Graphics." In the "Implications for practice" section of this paper, a typical semester's work will be discussed, but first, a unique learning opportunity involving historic texts presented itself and the OLS students leaped at this opportunity.
\end{abstract}

\section{Introduction}

During the 2009 Spring semester, Indiana University Purdue University Fort Wayne (IPFW) was host to an exhibition of fifty historic texts owned by the Remnant Trust Foundation [1]. Faculty members were encouraged to incorporate these historic texts into their courses and were invited to submit a proposal to receive funding for instructional materials. Sixteen faculty members had their proposals accepted and received this award.

The availability of the historic texts presented a unique learning opportunity for Organizational Leadership and Supervision students enrolled in OLS 324 which is an elective course for OLS majors. As future leaders and agents of change, leadership students were presented with the task of choosing, analyzing, and researching a historic text that exemplified their understanding of successful leadership practices.

Deliverables in the course were a research paper, a research poster, and a multimedia presentation. Each student's work was evaluated using detailed rubrics. Also, students wrote a two-page reflection paper and presented their work to their peers and faculty members at the end of the semester.

\section{The Remnant Trust}

The Remnant Trust is a public educational foundation comprised of over 900 original and first edition works which include manuscripts, books, pamphlets, and related documents on subjects related to individual liberty and human dignity.The Trust makes this world-class collection available to colleges, universities, and other organizations for use by students, faculty, scholars, and the general public. The astonishing and unique feature of the exhibition is that everyone is encouraged and able to touch, feel, and read the original works. On loan to IPFW were the Magna Charta (1576 edition, but it is interesting to note it was first issued in 1215), Cato's Letters (1724) by John Trenchard and Thomas Gordon, Common Sense (1776) by Thomas Paine, $A$ Vindication of the Rights of Woman (1792) by Mary Wollstonecraft, Benjamin Franklin's Pennsylvania Anti-Slavery Document (1787), Ralph Waldo Emerson's Essays: Self-Reliance (1841) and Abraham Lincoln's Gettysburg Address (1863) were just a few titles of note chosen from the collection [2].

\section{History meets technology}

Infusing history content into an application software course created an instructional challenge for the instructor, as well as, an intellectual challenge for the students. Both parties had to think outside of their comfort zones. Using the pedagogical method of project-basedlearning ( $\mathrm{PBL}$ ) proved to be the solution. PBL enabled the students to visualize and process the history content and actively create individualized projects based on their knowledge in 
the subject area of leadership.PBL can be generally defined as a model that organizes learning around projects [3]. This model is student-centered with the instructor taking the role of a facilitator. Blumenfeld et. al. states that there are two essential components to projects using PBL. First of all, a question or a problem serves to drive the activities that result in a succession of artifacts that conclude in a final product. Secondly, teachers can create questions and activities; however liberty must be given to the students to create artifacts that reflect their own developing knowledge [4].

In this course, each student's research drove the ensuing projects. The students needed to develop a thesis and an argument to support it. Their goal was to explain the significance and implications of their topic as it fits into what they have learned as an OLS major. The instructor set the requirements as to the various forms in which their research should be submitted, i.e., paper, poster, multimedia presentation. The instructor provided guidance in the areas of fleshing out a thesis statement and instructional help with the application software used in the course. In particular, students needed help learning how to use Adobe Presenter. This software program was new to all of the students. It was the first opportunity they had to turn their MS PowerPoint slides into a stand-alone multimedia presentation. Developing multimedia projects have proven to provide various positive outcomes. Multimedia can serve as an 'enabler and catalyst' to support the student in effectively using the tools to exhibit their creativity and problem solving skills [5]. Additionally, OLS students are learning a new presentation tool to use as they head out into the workforce as managers.

\section{The course}

The first week of the semester was spent introducing the students to the course objectives and the Remnant Trust exhibition. The objectives for this project fell within the Framework for the IPFW Baccalaureate Degree and the Vision of the Division of Organizational Leadership and Supervision. They were as follows:Students will have mastered the material in this course when they:

- acquire awareness and appreciation for the Remnant Trust documents

- synthesize leadership principles with the theme of individual liberty \& human dignity to conduct and evaluate research

- develop an understanding of core concepts related to manipulation of digital images

- demonstrate the ability to conceptualize, organize, plan \& execute multimedia projects

- demonstrate technical proficiency in using software for design and production tasks
- present research orally, in written form, and electronically as a multimedia presentation

The students were also introduced to the Remnant Trust Exhibit. A special display area was created in the campus library to house the historic texts. The instructor and the students visited the exhibit together to explore the offerings on loan. It was a memorable experience to be able to touch and hold manuscripts, books, and pamphlets that were centuries old. A graphic of the exhibit design can be seen in Figure 1.

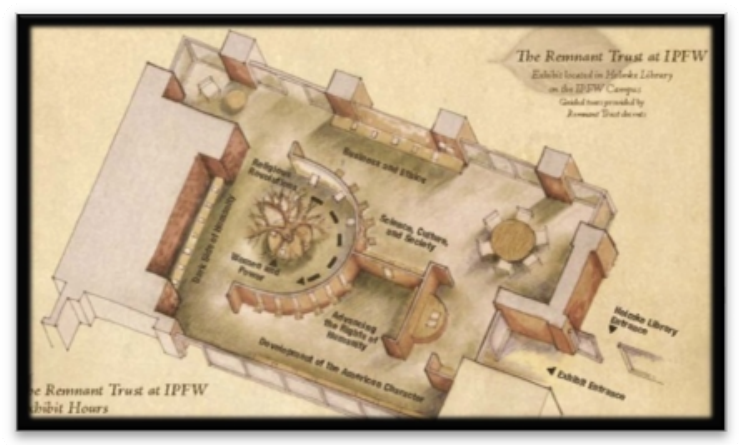

Figure 1. Remnant Trust exhibit design

To begin the coursework each student needed to write a paper based on the quintessence of a particular Remnant Trust document. The students felt uncomfortable and hesitant in choosing the topic for their project. It has been found that students experiencefeelings of uneasiness in the early stages of the implementation of project-based learning, however, most students feel more motivated as time elapses in the course [6]. Therefore, choosing the historic text and developing a thesis statement based on this information took time and energy. Students needed a few weeks to choose their primary resource and gather secondary resources.

During this time, the class made a visit to the campus writing center and campus technology resource lab named Studio $M$ for inspiration and encouragement. Even though these students were upperclassmen, each of them was struggling to develop the perfect thesis statement. The personnel at the writing center were instrumental in helping them focus their many thoughts on leadership in a particular direction. Studio M, on the other hand, a computer lab dedicated to help students with multimedia projects, provided them with a wellequipped computer laboratory with a helpful staff that was open seven days a week.

Also during these initial weeks of the semester, students were learning basic photo editing skills using Adobe Photoshop in the OLS computer classroom. These lessons were designed to prepare them to manipulate any graphic material they found to include in the next phases of the project: a research poster and multimedia presentation. Upon completion of the research paper, each student 
developed a very specific research poster summarizing his or her written report.

The final and ultimate goal was to have each student develop an engaging multimedia presentation based on their paper that included text, audio, and graphics. The results of these projects were multimedia packages that illustrated and expounded on the substance of these historic documents.

At the end of the semester, all 21 students presented their work to their peers and several faculty members. The audience was able to view each student's multimedia presentation and research poster. In addition, three students were selected to present their work at the annual IPFW Student Research and Creative Endeavor Symposium held on campus.These open presentations are viewed as a reward for the extra effort that most students put into their course projects [7].

\section{Assessment}

Each student's work was evaluated using detailed rubrics specifically designed to score a research paper, a poster, and a multimedia presentations. The course also included an introduction to the Photoshop software and writing assignments based on the lecture events. Special lecture events were scheduled on campus in conjunction with the Remnant Trust exhibition. The class attended three of these lectures. Hence, the scoring of the work was as follows: the Photoshop exercises and Lecture writings were worth $10 \%$ of the total grade, the research paper was worth $35 \%$ of the total grade, the research poster was worth $20 \%$ of the total grade, and the multimedia presentation was worth $35 \%$ of the total grade. Table 1 summarizes the assessment areas by project:

Table 1. Assessment areas by project

\begin{tabular}{|l|l|l|}
\hline Research Paper & Poster & $\begin{array}{l}\text { Multimedia } \\
\text { Presentation }\end{array}$ \\
\hline $\begin{array}{l}\text { Purpose and } \\
\text { Focus }\end{array}$ & Content & $\begin{array}{l}\text { Quality of } \\
\text { Content }\end{array}$ \\
\hline $\begin{array}{l}\text { Development } \\
\text { of Ideas }\end{array}$ & Graphics & $\begin{array}{l}\text { Multimedia } \\
\text { Elements }\end{array}$ \\
\hline $\begin{array}{l}\text { Organization } \\
\text { and_Sentence } \\
\text { structure }\end{array}$ & $\begin{array}{l}\text { Interesting } \\
\text { Attractive } \\
\text { Layout }\end{array}$ & $\begin{array}{l}\text { Information } \\
\text { Structure }\end{array}$ \\
\hline $\begin{array}{l}\text { Spelling and } \\
\text { Grammar }\end{array}$ & $\begin{array}{l}\text { Spelling and } \\
\text { Grammar }\end{array}$ & $\begin{array}{l}\text { Spelling and } \\
\text { Grammar }\end{array}$ \\
\hline $\begin{array}{l}\text { Language/ } \\
\text { Word Choice }\end{array}$ & $\begin{array}{l}\text { Mechanical } \\
\text { Elements }\end{array}$ \\
\hline References & References & References \\
\hline
\end{tabular}

\section{Discussion}

The projects created in this course were more than a review of history. Yes, the Remnant Trust exhibition at IPFW presented a unique learning opportunity for OLS students to observe and examine the content and the design of historic texts, but the OLS students went beyond examining the texts. This course challenged students to analyze how they could incorporate aspects of these documents into their modern leadership skill set. In other words, how are these documents still pertinent in the $21^{\text {st }}$ century? Students were able to think critically on the role of history in contemporary society [8].

After a few weeks of discussing how they needed to synthesize this material, the students came up with some exceptional thesis statements. For example, one student compared the writings in Cato's Letters to the U.S. Government's "Bailout Programs," another student discussed how today's businesses could learn from Thomas Paine's Common Sense when it comes to dealing with unethical behavior in the workplace, and another student discussed how the Magna Charta could be related to some of the employee rights and employer rights procedures and policies from the human resource perspective in today's society. Also, several students discussed how far the women's rights movement has come since Mary Wollstonecraft wrote A Vindication of the Rights of Woman in 1792. This is just a sampling of the exceptional ideas that were presented. The research papers were formatted using the report templates in WORD 2007 and printed and bound on heavy stock paper. An example of a bound paper can be seen in Figure 2.

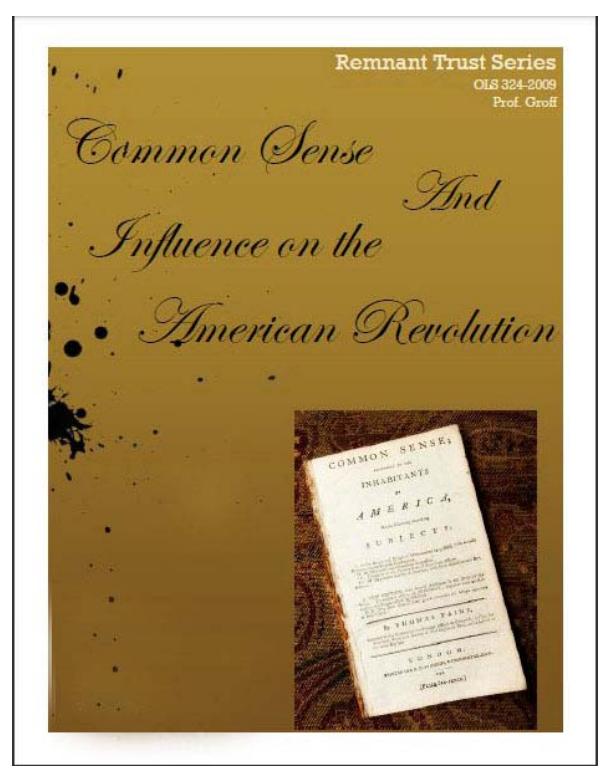

Figure 2. Research paper

After the research papers were written, each student summarized their work on a poster. This 
assignment was challenging because the students were unfamiliar with summarizing information from a 10-page paper so that it would fit on a single poster board. The poster had to be informative and visually appealing. The posters were formatted using the poster templates in PowerPoint 2007 and printed on a $20 \times 26$ inch foam board. Figure 3 is an example of a finished poster.

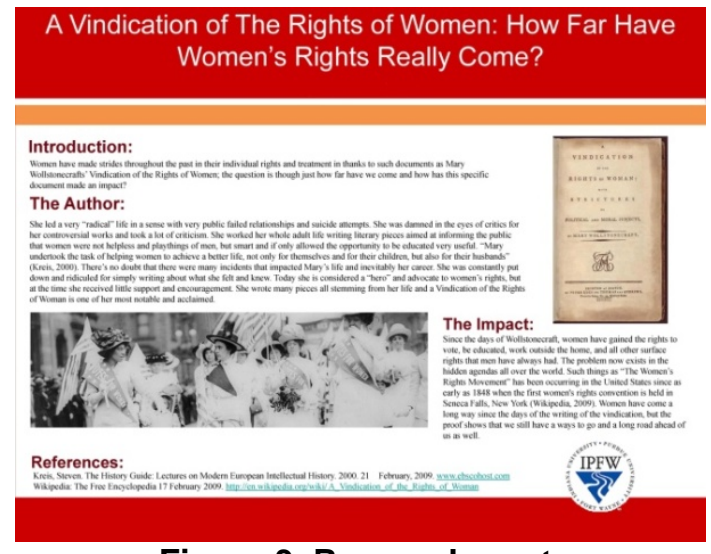

Figure 3. Research poster

After the posters were completed, the students used the Adobe Presenter software to create a standalone, multimedia presentation that when saved is formatted as an Adobe Flash file. They were now creating an electronic presentation of their papers that included text, graphics, and narrated by their own voices that could be easily posted to the Web. Figure 4 is the title slide of a final presentation.

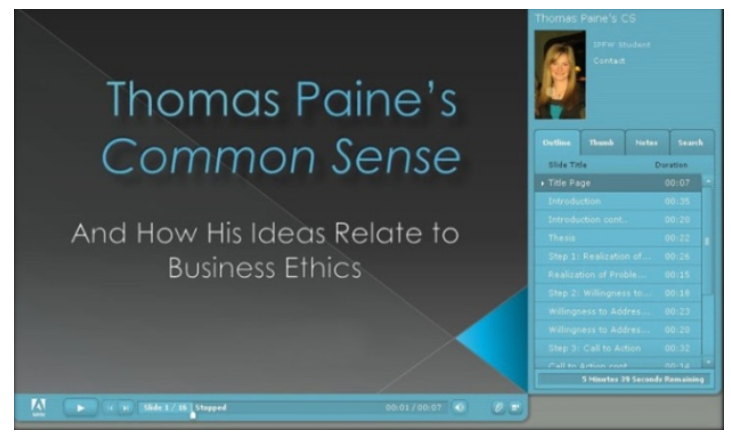

Figure 4. Final presentation

The binding of the reports and the printing of the posters were paid for using monies from the Remnant Trust grant. Funds were also used to provide refreshments for the final presentations and to buy additional headsets with microphones for the computer lab.

\section{Student reflection}

At the end of the course, each student wrote a reflection paper about their experiences in the course. Here are some comments from the students: "All of the projects from this semester went together very easily. Each piece that we completed built on to the piece before it which eliminated a lot of the guess work." They also enjoyed the multimedia part of the project, "I have written many research papers in my college career, but never have I been given the chance to bring that paper to life. I have learned a lot about women's suffrage and how to make a written document multimedia." "I actually learned a lot from this project. I not only learned a lot about the document of the Vindication and the content of the article, but I also learned how to incorporate it into different forms of presentation in the projects we did."

Some students acquired a new appreciation for the past, "This class has showed me that sometimes when you are looking for a solution for your company or life, sometimes the past is the best place to look. Many times you can use examples from the men and women that came before us and other times take those examples and add new features to them."

The class also attended the three lecture events that were hosted as part of the Remnant Trust Exhibition.The events helped thestudents become even more immersed in the historical content of the course. Here are a couple of comments from the students, "I also gained some additional knowledge from attending the Omnibus Theatre lectures; they were interesting and beneficial as well." "I really appreciated the opportunity to involve campus events in classroom learning. Many of these events occur during classes, and students are not allowed to attend. To me, that defeats the purpose (of having them)."

\section{Implications for practice}

Anytime that a student generates content via a report or a research paper, this material could easily be presented via a poster and a multimedia presentation. The software used for these projects is not discipline specific and the final projects could easily be put online for further review and learning opportunities.

The historic texts provided by the Remnant Trust Foundation created a unique learning opportunity, but during a typical semester in OLS 324, each student is asked to develop and create a presentation for a "client" using a real-life situation. OLS 324 students create on-demand presentations as part of a service learning component in the course. Service learning is a teaching method in which students become partners with someone in the community to fill a need. It provides a student with opportunities to use newly acquired skills and knowledge in real-life situations.This interaction can result in the students feeling that they are making a difference in their community. In a study done by Levesque-Bristol et. al. it was found that when students were directly involved with the people receiving the service, this experience increased their sense of "autonomy, competence, and relatedness and allowed them to take ownership of the project" [9]. These on-demand 
presentations can be used for e-learning or marketing experiences.

For a typical presentation, the client may supply all of the content or the student may help with the content, then the student creates an engaging, stand alone presentation using PowerPoint and Presenter to convey this information. The client not only provides content, but also feedback on how the student is doing. If the client doesn't use the presentation, the student is not penalized for this decision. Each student's work is evaluated using detailed rubrics specifically designed to score a multimedia presentation.

Over the years, there have been successful collaborations with both members of the academic community and the local community. Students have created a variety of presentations. Here is a very short list of presentations that have been developed:

- Assisted Living Center Dietary Unit Introduction: a student worked at an assisted living care center and recognized a need for a presentation to introduce prospective residents and their families to the "food" portion of their stay. The student worked with the staff dietician to create a presentation. An unforeseen benefit of this project was that the current residents who were asked to be part of this project enjoyed viewing the presentation too. They enjoyed watching themselves and the staff in this informative and upbeat presentation.

- Belt Manlift Training: a student worked as a safety officer at a local factory and needed to put together a training presentation on how the use the belt manlift at this facility. The training presentation included a short interactive quiz over the material covered in the presentation. The Presenter software contains a built in quiz component. The student's immediate supervisor served as the client. Figure 5 is the title slide of this training presentation.

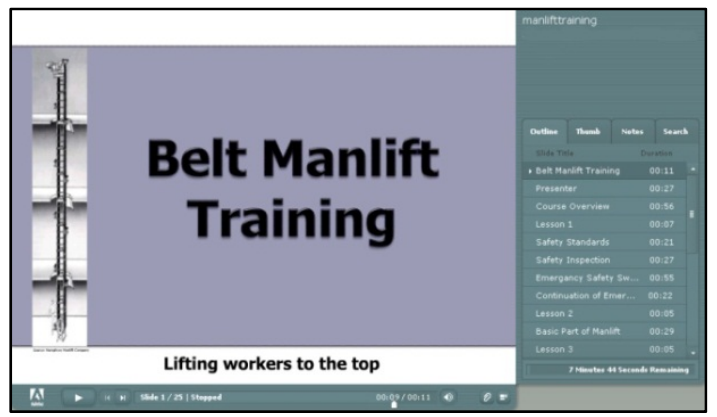

Figure 5. Training presentation

- Basketball Camp Recruitment Presentation: a student created a presentation to help recruit young girls to participate in a summer basketball camp. The client was the director and coach of the basketball camp. The presentation was designed to grab the attention of girls aged $9-13$ and convince them the sign up for the camp. It was designed using lots bright colors, photographs and was filled with inspiring quotes. Figure 6 is the poster created for this recruitment presentation.

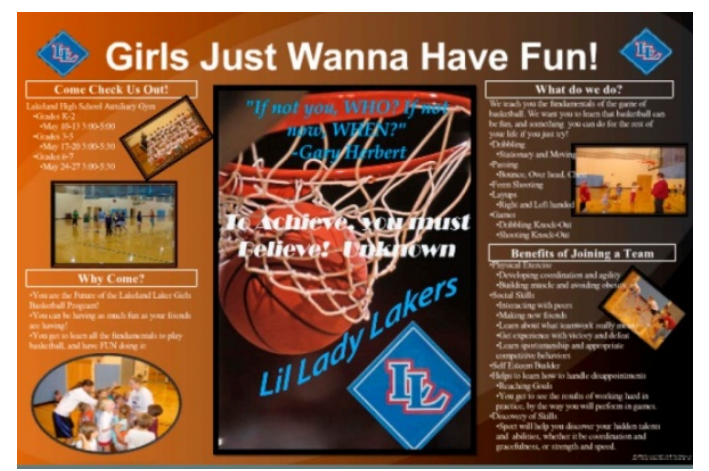

Figure 6. Recruitment poster

- IPFW Engineering Senior Design Project: OLS students work with engineering students to capture their senior design project in a standalone presentation. These projects are usually funded by companies in the community and represent two semesters of research, design, building a working prototype. The engineering team serves as the client. These projects also represent collaboration between students with highly technical skills and students with exceptional organizational skills. This is usually the first time the engineering students have to explain their work to a non-technical audience. Many times it takes several meetings to find a common ground and to develop these presentations. An unexpected outcome of this collaboration effort is that the Engineering Department is able to use the presentations as recruitment material for prospective students [10]. Figure 7 is the title slide of a collaboration presentation.

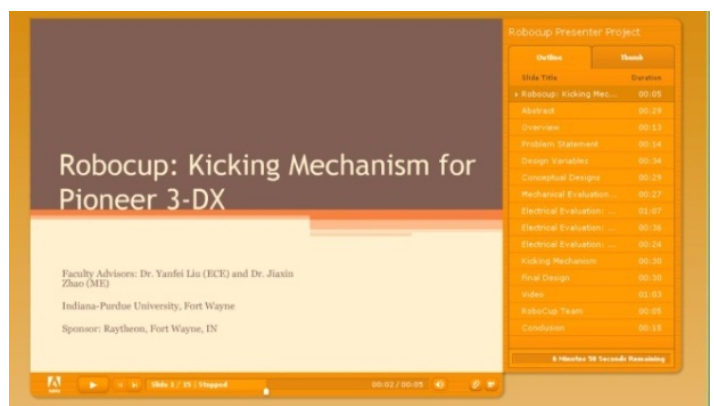

Figure 7.Collaboration presentation

- Be What's Possible: a student worked for a local retail store whose management wanted employees to volunteer in the community. The student with her manager's help searched for local organizations that needed volunteer help. This presentation highlighted the need for volunteers with Habitat for Humanity, American Red Cross, Junior Achievement, and other local agencies. This presentation was 
created shortly after Hurricane Katrina hit New Orleans and the student included a video of the devastation caused by this natural disaster and the need for volunteer help locally and beyond.

\section{Conclusion}

In general, students can benefit from designing posters and comprehensive stand-alone multimedia presentations because it provides them with an opportunity to express their ideas visually and it improves both their communication and technical skills. The Remnant Trust project was designed to provide students with the opportunity to use their problem-solving and creativity skills to conduct research in the field of leadership using historic texts and presentation technology tools. The service learning projects created in a typical semester provide students with the opportunity to use their new skills in real-life situations. The purpose of the presentation may vary, but in today's high tech world presentations that can be viewed electronically anytime and in any location are in demand.

\section{References}

[1] The Remnant Trust at IPFW website.[Online]. Available: http://remnanttrust.ipfw.edu. [accessed September 10, 2009].

[2] The Remnant Trust Foundation website.[Online]. Available:http://www.theremnanttrust.com.[accessed September 10, 2009].

[3] J. Thomas, A Review of Research on Project-Based Learning.March 2000. [Online]. Available: http://www.bie.org/research/study/review_of_project_base d_learning_2000. [accessedSeptember 10, 2009].

[4]P. Blumenfeld, E. Soloway, R. Marx, J. Krajcik, M. Guzdial, and A. Palincsar, "Motivating Project-Based Learning: Sustaining the Doing, Supporting the Learning”, Educational Psychologist, vol.26, no.3/4, pp. 369.Summer/Fall 1991.[Online]. Available: Academic Search Premier, EBSCOhost,http://search.ebscohost.com. [accessedSeptember 10, 2009].

[5] M. Neo and T.-K Neo, "Engaging students in multimedia-mediated Constructivist learning - Students' perceptions”, Educational Technology \& Society, vol.12, no.2, pp. 254-266.April 2009. [Online]. Available: Academic Search Premier, EBSCO host,http://search.ebscohost.com.[accessed September 24, 2009].

[6] Y. Gülbahar and H. Tinmaz, "Implementing ProjectBased Learning and E-Portfolio Assessment in an Undergraduate Course", Journal of Research on Technology in Education, vol.38, no.3, pp. 309-327. Spring 2006. [Online]. Available: Academic Search Premier, EBSCOhost,http://search.ebscohost.com. [accessed November 17, 2009].
[7] T. Dublin and K. Kish Sklar, "Democratizing Student Learning: The 'Women and Social Movements in the United States, 1820-1940' Web Project at SUNYBinghamton”, History Teacher, vol.35, no.2, pp. 163. February 2002. [Online]. Available: Academic Search Premier, EBSCOhost,http://search.ebscohost.com. [accessed September 10, 2009].

[8] S. Amirell, "Descent from the Ivory Tower: A Group Assignment for Studying the Role of History in Society." History Teacher.Vol. 42, no. 4, pp. 441-456. August 2009. [Online]. Available: Academic Search PremierEBSCOhost, http://search.ebscohost.com. [accessed January 10, 2010].

[9] C. Levesque-Bristol, T. Knapp, and B. Fisher, "The Effectiveness of Service-Learning: It's Not Always What You Think.” Journal of Experiential Education, vol.33, no.3, pp 208-224. 2010. [Online]. Available: Academic Search Premier, EBSCO host, http://search.ebscohost.com. [accessed January 20, 2011].

[10] C.A. Pomalaza-Ráez and B.H. Groff, "Dissemination of Capstone Design Projects through Interdisciplinary Collaboration", 2008 Annual ASEE IL/IN Section Conference, "Engineering Education at the Crossroads", Rose-Hulman Institute of Technology, Terre Haute, IN, April 3 - 5, 2008. 